\title{
Risk of herpes zoster among diabetics: a matched cohort study in a US insurance claim database before introduction of vaccination, 1997-2006
}

\author{
A. P. Guignard • M. Greenberg • C. Lu • \\ D. Rosillon $\cdot$ V. Vannappagari
}

Received: 30 January 2014 / Accepted: 9 June 2014/Published online: 29 June 2014

(c) Springer-Verlag Berlin Heidelberg 2014

\begin{abstract}
Purpose To assess whether diabetes is a risk factor for herpes zoster (HZ).

Methods We conducted a retrospective cohort study using the Integrated Health Care Information Services database, during the period 1997-2006. A type I diabetes cohort, a type II diabetes cohort and two non-diabetic cohorts matched for date of enrolment and duration of follow-up were defined. HZ and diabetes were defined using a combination of ICD-9 and prescription drug codes. Individuals with immunosuppressive conditions or treatments were excluded. Cox Proportional Hazards regression analysis using a stepwise method with backward elimination was applied to estimate the hazard ratios (HR) of HZ, including age, gender and co-morbidities as covariates.

Results The study population comprised 380,401 and 20,397 type II and type I diabetic subjects respectively, as well as 1,521,604 and 81,588 matched controls. The median ages were 55, 35, 33 and 29 years, respectively. $\mathrm{HZ}$ incidence was $4.59,2.13,1.97$, and 1.82 per 1,000 person-years, respectively. There was no evidence of an impact of type I diabetes on the risk of HZ. Type II diabetes was associated with an increased risk for $\mathrm{HZ}$ in
\end{abstract}

Electronic supplementary material The online version of this article (doi:10.1007/s15010-014-0645-x) contains supplementary material, which is available to authorized users.

\footnotetext{
A. P. Guignard $(\bowtie) \cdot$ M. Greenberg · D. Rosillon

Global Epidemiology, GlaxoSmithKline Vaccines, Building

WN23-E1, Avenue Fleming, 20, 1300 Wavre, Belgium

e-mail: adrienne.x.guignard@gsk.com

C. Lu $\cdot$ V. Vannappagari

Worldwide Epidemiology, GlaxoSmithKline (R\&D), Five

Moore Drive, 17.2131, Research Triangle Park, NC 27709-3398,

USA
}

subjects $\geq 65$ (HR 3.12; $95 \%$ CI 2.77-3.52, adjusted for gender) and in subjects between 40 and 64 (HR 1.51; $95 \%$ CI 1.42-1.61) years of age. Cardiac disease and chronic pulmonary disease were also risk factors (HR 1.92; $95 \%$ CI $1.73-2.13$ and HR 1.52 ; $95 \%$ CI $1.38-1.67)$ in nondiabetic subjects.

Conclusions This study suggests that type II diabetes is associated with an increased risk of developing HZ, which was particularly high in adults 65 years and older and moderately increased in adults under 65 years of age.

Keywords Herpes zoster - Post herpetic neuralgia . Diabetes $\cdot$ Risk factor $\cdot$ Epidemiology

\section{Introduction}

Herpes zoster (HZ) or "shingles" is a disease resulting from the reactivation of latent varicella zoster virus (VZV). About one million cases of $\mathrm{HZ}$ occur annually in the US [1]. The most common complication is post-herpetic neuralgia (PHN) in which neuropathic pain remains long after the $\mathrm{HZ}$ lesions have healed and often persists for several months. Herpes zoster ophthalmicus (HZO) accounts for $10-20 \%$ of $\mathrm{HZ}$ cases and is more often associated with chronic and detrimental sequelae, in comparison with other dermatomal manifestations of HZ [2]. Rare visceral and neurological complications such as encephalitis or myelitis have also been reported [3].

The waning of virus-specific cell-mediated immunity (CMI) is believed to be a major cause of VZV reactivation. This can occur as part of the aging process or as a result of medical conditions associated with immunosuppression such as HIV infection, transplantation, cancer, and immune mediated diseases [4-9]. At the population level, about 
two-thirds of HZ cases occur in adults 50 years and older [10] and approximately $90 \%$ of $\mathrm{HZ}$ cases occur among otherwise immunocompetent individuals (of all ages) without any identified immunosuppressive condition or treatment [11, 12]. While the causes of $\mathrm{HZ}$ are imperfectly understood, additional risk factors include mechanical trauma and psychological stress, female gender, and white race (compared to black race) [1, 13]. An association between diabetes and $\mathrm{HZ}$ is supported by observations of Okamoto et al. [14] who showed that subjects with diabetes between 41 and 79 years had significantly lower cell mediated immunity to varicella zoster virus than did healthy individuals. Epidemiological studies investigating the association between $\mathrm{HZ}$ and diabetes are few and have yielded contradictory results, with studies suggesting that diabetes is a risk factor for HZ [15-17] and others failing to demonstrate a statistically significant association $[5,6,18]$. Most of these studies addressed multiple risk factors for $\mathrm{HZ}$, among which figured diabetes. Our objective was to examine the association between $\mathrm{HZ}$ and type I and type II diabetes in a large US insurance claim database.

\section{Methods}

Study design and data source

We conducted a retrospective matched cohort study using the Integrated Health Care Information Services database (IHCIS), a fully de-identified database that includes the medical history of more than 74 million individuals from 46 health plans in the United States. The study period, 1 January 1997 to 25 May 2006, represents the 10 years prior to the introduction of Zostavax ${ }^{\circledR}$, a vaccine to prevent $\mathrm{HZ}$ in adults aged 60 years and older, in the United States. Four study cohorts were defined: a type I diabetes cohort, a type II diabetes cohort and two comparative cohorts of non-diabetics. The diabetes type I and II cohorts comprised all diabetic subjects in the database with at least 12 months of contribution to the database after the first diagnosis code for diabetes, excluding individuals with a treatment or disorder causing immunodeficiency (chemotherapy/radiation therapy, systemic steroids, immunosuppressive drugs, organ transplants, HIV, cancers, immunodeficiency disorders and autoimmune disease), renal disease (other than diabetic nephropathy), hepatic disease, metabolic syndrome, and individuals with a history of $\mathrm{HZ}$ before diagnosis of diabetes. Four non-diabetic subjects per control cohort were matched to each type I and II diabetic subject on the date of entry (month and year) into the database and the duration of follow-up (in months), applying the same exclusion criteria as for the diabetic subjects.
Case definitions

Diabetic subjects were identified based on ICD-9 codes, as described in the Appendix. Criteria were applied to distinguish between type I and type II diabetes for subjects with no fifth digit in ICD-9 code: a subject with any oral antidiabetic drugs would be classified as a type II diabetic patient, a diabetic subject less than 20 years of age and on insulin would be classified as a type I diabetic patient. Subjects with no fifth digit in ICD-9 codes over 20 years of age and on insulin only were excluded, as the classification could not be made accurately.

A primary episode of $\mathrm{HZ}$ was defined by a first appearance of a diagnostic ICD-9 code for HZ (053.x) occurring 3 months or more after entry into the database and before 25 May 2006. Codes 053.12 for post-herpetic trigeminal neuralgia and 053.13 for post-herpetic polyneuropathy were excluded because of the increased potential for these cases to represent sporadic long-term follow-up for a prior $\mathrm{HZ}$ episode. Cases of $\mathrm{HZ}$ ophtalmicus were identified through specific ICD-9 codes listed in the Appendix.

Post-herpetic neuralgia was defined using the following criteria: (1) the presence of an ICD-9 code for HZ followed, within 3 months, by an ICD-9 code indicative of PHN 053.12 or 053.13 , or (2) the presence of an ICD-9 code for $\mathrm{HZ}$ followed by a PHN medication for more than 30 days starting within 30 days after the $\mathrm{HZ}$ diagnosis, or (3) the presence of an ICD-9 code for HZ followed, within 3 months, by the appearance of an ICD-9 code for chronic pain.

Co-morbidities and immunocompromising conditions were identified through ICD-9 codes indicative of the disease or a transplantation procedure (Appendix).

\section{Selection of control groups}

Type I and type II diabetic subjects were matched to four non diabetic subjects on the date of entry (month and year) into the database and the length of follow-up time (in months). As for diabetic subjects, controls were excluded if they had a disease or treatment causing immunodeficiency, renal or hepatic disease, metabolic sydrome.

Statistical analysis

The follow-up period began with the index date, which was defined as the date of the first diabetes-specific ICD-9 code for individual diabetic subjects. This index date was also assigned to matched non-diabetics. The follow-up period for all cohorts continued until the first $\mathrm{HZ}$ event, the date of introduction of the $\mathrm{HZ}$ vaccine Zostavax ${ }^{\mathrm{TM}}$ (Merck \& Co., Inc) in the United States (25 May 2006), or until lost-to- 
Table 1 Characteristics of the study population

\begin{tabular}{lllll}
\hline Characteristics & $\begin{array}{l}\text { Type II } \\
\text { diabetes }\end{array}$ & $\begin{array}{l}\text { Non-diabetics matched } \\
\text { with type II diabetes }\end{array}$ & $\begin{array}{l}\text { Type I } \\
\text { diabetes }\end{array}$ & $\begin{array}{l}\text { Non-diabetics matched } \\
\text { with type II diabetes }\end{array}$ \\
\hline $\begin{array}{l}\text { Number of subjects } \\
\text { Median age, years }\end{array}$ & 380,401 & $1,521,604$ & 20,397 & 81,588 \\
$\quad$ (range) & $55.0(0-82)$ & $33.0(0-82)$ & $35.0(0-82)$ & $29.0(0-82)$ \\
Age category, $n(\%)$ & & & & \\
$<$ 18 years & $5,056(1.3)$ & $481,366(31.6)$ & $4,753(23.3)$ & $27,570(33.8)$ \\
18-29 years & $11,951(3.1)$ & $208,422(13.7)$ & $3,414(16.7)$ & $13,237(16.2)$ \\
30-39 years & $34,272(9.0)$ & $217,176(14.3)$ & $3,938(19.3)$ & $12,431(15.2)$ \\
40-49 years & $75,326(19.8)$ & $233,131(15.3)$ & $3,092(15.2)$ & $12,145(14.9)$ \\
50-64 years & $182,863(48.1)$ & $219,050(14.4)$ & $3,165(15.5)$ & $10,329(12.7)$ \\
$\geq 65$ years & $70,933(18.7)$ & $162,459(10.7)$ & $2,035(10.0)$ & $5,876(7.2)$ \\
Gender ratio M/F, $n(\%)$ & & & \\
F & $156,802(41.3)$ & $741,357(48.7)$ & $9,613(47.1)$ & $39,709(48.7)$ \\
M & $223,599(58.8)$ & $780,247(51.3)$ & $10,784(52.9)$ & $41,879(51.3)$ \\
Follow-up time (months) & & & $39.3 \pm 21.4$ & $39.3 \pm 21.4$ \\
Mean \pm SD & $44.5 \pm 20.1$ & $44.5 \pm 20.1$ & 35.0 & 35.0 \\
Median & 44.0 & 44.0 & & \\
\hline
\end{tabular}

follow up, whichever came first. Incidence was calculated as the number of events divided by the sum of the persontime contributed by each qualified study participant in the diabetic and control cohorts. Stratum specific rates, where appropriate, and rate ratios comparing incidence rates between diabetic and control cohort were computed. LogRank tests were used to compare the two groups, with a $p$ value under 0.05 considered significant. Cox Proportional Hazards regression analysis was applied to estimate the hazard ratios (HR) of $\mathrm{HZ}$ associated with type I and type II diabetes. These results were adjusted for age, gender and other potential covariates identified through univariate analyses. Age was categorized as <18, 18-29, 30-39, 40-49, 50-64 and $\geq 65$ years. A stepwise method with backward elimination applied to the full model was used to select covariates to be included in the final model. Covariates remained in the model only if the $p$ value was lower than 0.05 . The proportional hazards assumption was assessed using the goodness of fit testing approach with $p$ value significant at $<0.05$. Results from the multivariable models were expressed as adjusted hazard ratios with $95 \%$ CIs.

\section{Results}

The study population comprised 380,401 and 20,397 type II and type I diabetic subjects respectively, as well as 1,521,604 and 81,588 control subjects. Characteristics of the population are described in Table 1. Subjects in the type II diabetes cohort were older and included more males than subjects in the three other cohorts, for which the age distribution and sex ratio were similar.
Crude HZ incidence was 4.59, 2.13, 1.97, and 1.82 per 1,000 person-years (PY) in the type II and I diabetic and matched cohorts, respectively. The age-specific incidence of $\mathrm{HZ}$ is described in Table 2. In all cohorts, $\mathrm{HZ}$ incidence increased with age. In both diabetic cohorts, $\mathrm{HZ}$ was more frequent in women than in men. In the various cohorts, the proportion of $\mathrm{HZ}$ cases with $\mathrm{HZ}$ ophtalmicus ranged between 4-9 \% and 2-7 \% developed PHN. The incidence of PHN was 0.19 (95\% CI 0.15-0.23) and 0.34 (95\% CI $0.27-0.43)$ per 1,000 PY in type II diabetics aged 50-64 years and older than 65 years, respectively and 0.12 (95\% CI 0.09-0.16) in the control cohorts for the same age groups.

Type II diabetes was associated with an increased risk for HZ, with age acting as an effect modifier (statistically significant age-by-type II diabetes interaction, $p<0.0001)$. The HR of HZ associated with type II diabetes was 3.12 (95\% CI 2.77-3.52) in subjects $\geq 65$ years of age and 1.51 (95\% CI 1.42-1.61) in subjects between 40 and 64 years of age, adjusting for gender and comorbidities (Table 3). Cardiac disease and chronic pulmonary disease were identified as other risk factors for $\mathrm{HZ}$ (HR 1.92; $95 \%$ CI 1.73-2.13 and HR 1.52; $95 \%$ CI $1.38-1.67$ in non-diabetic subjects) and modified the effect of type II diabetes on the risk of HZ. Figure 1 illustrates the HR of developing HZ associated with diabetes and other co-morbidities compared with "healthy" subjects (neither diabetic nor co-morbidities by age). Subjects having multiple co-morbidities (COPD or coronary disease in addition to type II diabetes) had higher risk than subjects with a single condition but the total risk was lower than the sum of each individual risk. The risks are not additive. 
Table 2 Herpes zoster incidence (cases/1,000 person-years) in the type I and II diabetics cohorts and control groups, stratified by gender and age

\begin{tabular}{|c|c|c|c|c|c|}
\hline Disease & Group & $\begin{array}{l}\text { Type II diabetes } \\
(n=380,401)\end{array}$ & $\begin{array}{l}\text { Non-diabetics matched with } \\
\text { type II diabetes }(n=1,521,604)\end{array}$ & $\begin{array}{l}\text { Type I diabetes } \\
(n=20,397)\end{array}$ & $\begin{array}{l}\text { Non-diabetics matched with } \\
\text { type I diabetes }(n=81,588)\end{array}$ \\
\hline \multirow[t]{12}{*}{ Herpes zoster } & Total & $\begin{array}{l}4.59(4.45-4.74) \\
n=380,401\end{array}$ & $\begin{array}{l}1.97(1.92-2.02) \\
n=1,521,604\end{array}$ & $\begin{array}{l}2.13(1.72-2.6) \\
n=20,397\end{array}$ & $\begin{array}{l}1.82(1.64-2.01) \\
n=81,588\end{array}$ \\
\hline & Gender & & & & \\
\hline & M & $\begin{array}{l}4.03(3.86-4.21) \\
n=223,599\end{array}$ & $\begin{array}{l}1.77(1.71-1.83) \\
n=780,247\end{array}$ & $\begin{array}{l}1.94(1.42-2.6) \\
n=10,784\end{array}$ & $\begin{array}{l}1.68(1.45-1.95) \\
n=41,879\end{array}$ \\
\hline & $\mathrm{F}$ & $\begin{array}{l}5.4(5.16-5.65) \\
n=156,802\end{array}$ & $\begin{array}{l}2.18(2.11-2.25) \\
n=741,357\end{array}$ & $\begin{array}{l}2.34(1.72-3.1) \\
n=9,613\end{array}$ & $\begin{array}{l}1.96(1.7-2.25) \\
n=39,709\end{array}$ \\
\hline & Age gro & (years) & & & \\
\hline & $<18$ & $\begin{array}{l}1.02(0.53-1.78) \\
n=5,056\end{array}$ & $\begin{array}{l}1.13(1.07-1.19) \\
n=481,366\end{array}$ & $\begin{array}{l}1.03(0.51-1.84) \\
n=4,753\end{array}$ & $\begin{array}{l}1.11(0.88-1.38) \\
n=27,570\end{array}$ \\
\hline & $18-29$ & $\begin{array}{l}2.93(2.31-3.68) \\
n=11,951\end{array}$ & $\begin{array}{l}1.48(1.37-1.59) \\
n=208,422\end{array}$ & $\begin{array}{l}1.49(0.71-2.74) \\
n=3,414\end{array}$ & $\begin{array}{l}1.4(1.03-1.86) \\
n=13,237\end{array}$ \\
\hline & $30-39$ & $\begin{array}{l}2.22(1.9-2.57) \\
n=34,272\end{array}$ & $\begin{array}{l}2.09(1.97-2.22) \\
n=217,176\end{array}$ & $\begin{array}{l}2.08(1.21-3.33) \\
n=3,938\end{array}$ & $\begin{array}{l}1.78(1.36-2.29) \\
n=12,431\end{array}$ \\
\hline & $40-49$ & $\begin{array}{l}3.17(2.91-3.44) \\
n=75,326\end{array}$ & $\begin{array}{l}2.34(2.21-2.47) \\
n=233,131\end{array}$ & $\begin{array}{l}3.02(1.85-4.67) \\
n=3,092\end{array}$ & $\begin{array}{l}2.45(1.94-3.06) \\
n=12,145\end{array}$ \\
\hline & $50-64$ & $5.01(4.8-5.23)$ & $3.55(3.39-3.72)$ & $3.2(2.01-4.85)$ & $3.39(2.71-4.19)$ \\
\hline & & $n=182,863$ & $n=219,050$ & $n=3,165$ & $n=10,329$ \\
\hline & $\geq 65$ & $\begin{array}{l}6.54(6.17-6.94) \\
n=70,933\end{array}$ & $\begin{array}{l}2.4(2.24-2.57) \\
n=162,459\end{array}$ & $\begin{array}{l}2.77(1.48-4.74) \\
n=2,035\end{array}$ & $\begin{array}{l}2.38(1.6-3.39) \\
n=5,876\end{array}$ \\
\hline
\end{tabular}

Table 3 Hazard ratio for herpes zoster event associated with type II diabetes, cardiac disease, COPD and gender

\begin{tabular}{|c|c|c|c|}
\hline Effect & HR & \multicolumn{2}{|c|}{$95 \%$ CI } \\
\hline \multicolumn{4}{|l|}{ Diabetes Type II in } \\
\hline $\begin{array}{l}\text { Subjects age } 18-29 \text {, age } 40-49 \text {, and age } 50-64 \\
\text { (ref. non type II diabetics, same age) }\end{array}$ & 1.51 & 1.41 & 1.61 \\
\hline $\begin{array}{l}\text { Subjects age }<18 \text { (ref. non type II diabetics, } \\
\text { same age) }\end{array}$ & 0.78 & 0.43 & 1.42 \\
\hline $\begin{array}{l}\text { Subject at age } 30-39 \text { (ref. non type II diabetics, } \\
\text { same age) }\end{array}$ & 1.01 & 0.84 & 1.2 \\
\hline $\begin{array}{l}\text { Subjects at age } \geq 65 \text { (ref. non type II diabetics, } \\
\text { same age) }\end{array}$ & 3.12 & 2.77 & 3.52 \\
\hline $\begin{array}{l}\text { Cardiac disease subjects (ref. non type II } \\
\text { diabetics with cardiac disease) }\end{array}$ & 0.91 & 0.8 & 1.04 \\
\hline $\begin{array}{l}\text { COPD subjects (ref. non type II diabetics with } \\
\text { COPD) }\end{array}$ & 1.14 & 0.98 & 1.33 \\
\hline $\begin{array}{l}\text { Cardiac disease in non-diabetic subjects (ref. non } \\
\text { cardiac disease, non-diabetic) }\end{array}$ & 1.92 & 1.73 & 2.13 \\
\hline $\begin{array}{l}\text { COPD in non-diabetic subjects (ref. non COPD, } \\
\text { non diabetic) }\end{array}$ & 1.52 & 1.38 & 1.67 \\
\hline Gender: male (ref. female) & 0.78 & 0.75 & 0.82 \\
\hline
\end{tabular}

Note: because of a statistically significant interaction between the effect of diabetes type II and age and other comorbidity, HR were calculated per age class and comorbidity status

There was no evidence of an impact of type I diabetes on the risk of $\mathrm{HZ}$. The $\mathrm{HR}$ for $\mathrm{HZ}$ among type I diabetic subjects was in the range $0.70-1.94$ across age groups.

\section{Discussion}

There is contradictory evidence on the potential risk that type I and type II diabetes may pose for the occurrence of HZ. This study suggests that type II diabetes is associated with an increased risk of developing HZ. The magnitude of the risk associated to type II diabetes is conditioned by the age of the individual and the presence of comorbidities: it was highest in type II diabetics 65 years or older, who had a three-fold increased risk of developing $\mathrm{HZ}$ compared to non-diabetics. Type II diabetics between 40 and 64 were $50 \%$ more likely to develop HZ compared with non-diabetics of the same age. Type I diabetes was not identified as an independent risk factor for HZ.

These findings compare with another retrospective study conducted in Israel [15] which found that diabetes was associated with an increased odds of $\mathrm{HZ}(\mathrm{OR}=1.53$; $95 \%$ CI 1.44-1.62), comparing 22,294 HZ cases with 88,895 controls. Another recent primary health care database analysis in Spain concluded that diabetics ( $n=26,793)$ presented an adjusted relative risk of 2.1 (95\% CI 1.9-2.4) of developing HZ compared to nondiabetics [17]. These studies, as ours, were designed to assess the association between $\mathrm{HZ}$ and diabetes. However, our study included a larger population of diabetics and differentiated type I and type II diabetics. In the US Market Scan database (subjects from 20 to 64 years of age), the 
Fig. 1 Hazard ratio for developing herpes zoster associated with type II diabetes and co-morbidities (reference "healthy" subjects, without diabetes nor co-morbidity), by subject age

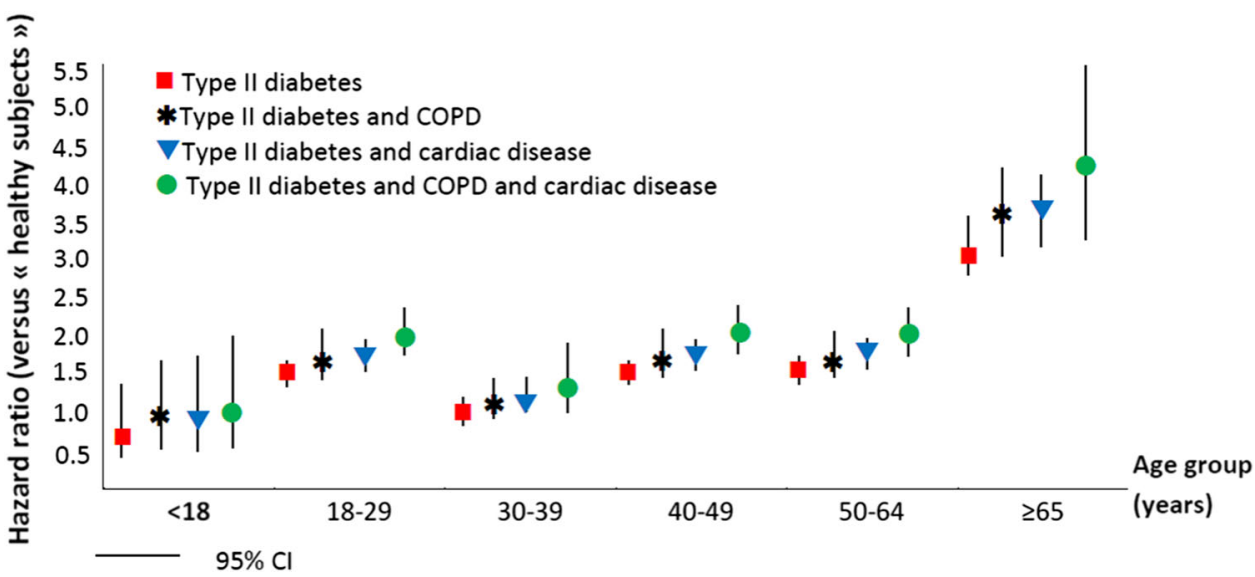

OR associated with diabetes was 1.06 (1.03-1.09), diabetes being considered as a risk factor among eight other chronic conditions [16]; this study did not include adults over 65 years of age, in whom we identified the strongest effect of type II diabetes on the risk of HZ. Some studies did not find any link between $\mathrm{HZ}$ and diabetes. Of note, they were not specifically designed to address this question or were conducted in populations with specific co-comorbidities [6, 19]. In a prospective matched case-control study Lasserre et al. [18] found that diabetes was associated with $\mathrm{HZ}$ in the univariate analysis, but the association was not significant in the multivariate analysis. Not taking into account an interaction between age and type II diabetes may result in underestimating the effect of type II diabetes in the elderly.

Data from Japan comparing 63 patients with diabetes and 67 healthy volunteers showed that patients with diabetes had significantly lower CMI to VZV than did healthy individuals [14]. CMI is critical in controlling reactivation of the VZV virus, this may explain the increased risk for developing HZ observed in diabetics. This study did not observe a difference of anti-VZV antibody titer in patients with diabetes and healthy volunteers.

Our study also highlighted that other chronic conditions such as cardiac diseases and chronic pulmonary diseases are risk factors for $\mathrm{HZ}$ development. A cohort study using data from the Taiwan Longitudinal Health Insurance Database has also suggested a potential association between chronic obstructive pulmonary disease and $\mathrm{HZ}$ [20], with an adjusted HR of 1.68 (95 \% CI 1.45-1.95), the risk of $\mathrm{HZ}$ being greatest for patients with COPD using oral steroids. Similarly, Joesoef et al. showed evidence of COPD as a risk factor for $\mathrm{HZ}$ (adjusted OR 1.35, $95 \% \mathrm{CI}$ 1.23-1.47). The same study found coronary diseases to modestly increase the risk of $\mathrm{HZ}(1.17,95 \% \mathrm{CI}$ 1.11-1.22). Our results show that subjects having multiple co-morbidities (COPD or coronary disease in addition to type II diabetes) had higher risk than subjects with a single condition but the total risk was lower than the sum of each individual risk.

We also observed a higher incidence of HZ among women than men. This has been described elsewhere. The Shingles Prevention Study indicated that the incidence of confirmed HZ cases in a cohort of immunocompetent persons aged $>60$ years was $11 \%$ higher among women (11.8 vs 10.7 cases per 1,000 PY in women and men, respectively) [21]. A review of $\mathrm{HZ}$ epidemiology in Europe showed that incidence rates are systematically higher among women than men (male/female ratio around 1.4), and this difference increased with age [22]. Other studies in North America have also shown an age standardized excess of zoster among women [23]. The reason is not known. One hypothesis is that women might be more likely to seek medical advice, thereby causing a higher reporting rate. However, this difference has been observed in a phase III clinical trial where active case finding has been implemented, with similar procedures for men and women. Another potential explanation is the role of a biological mechanism by which women would be more susceptible to VZV reactivation.

Risk factors for $\mathrm{HZ}$ are still imperfectly understood. The role of aging and underlying immunocompromising conditions is well recognized. However, the impact of chronic diseases is still unclear. Multiple chronic conditions have been identified as potential risk factors for $\mathrm{HZ}$, including lung disease and COPD [6, 19, 20], liver disease [6], renal failure [6], depression [16, 18, 24], coronary diseases, hyperlipidemia, osteoarthritis, hypothyroism [16]. For many of those, the population-attributable fraction, i.e. the excess of $\mathrm{HZ}$ cases that could be attributable to the presence of the conditions, seems modest, ranging between 0.24 and $2.89 \%$. Further studies would be needed to confirm their association with $\mathrm{HZ}$ and explain the biological mechanism involved. This multiplicity of risk factors also questions the prevention messages around vaccination against HZ, which may need to target not only older adults 
but also populations with co-morbidities which have a substantial impact on the risk of $\mathrm{HZ}$.

In our study, between 2 and $7 \%$ of HZ cases developed PHN, which was defined using an algorithm combining ICD-9 codes and prescription drugs. In prospective studies, PHN is reported among $10-20 \%$ of $\mathrm{HZ}$ cases, its frequency and duration increasing with older age [10]. There is no standard definition of PHN and the proportion of patients reported to develop PHN varies across studies depending on the definition used and the characteristics (age in particular) of the study population. Identifying PHN in administrative databases is further complicated by the fact that the ICD-9 classification did not include specific PHN codes. Recent database studies reported proportions of $\mathrm{HZ}$ patients with PHN ranging from $4.3 \%$ [25] in the US Market Scan Research Database to $6.2 \%$ in primarycare database and national hospital-discharge records covering four regions in Italy [11], which is in the range of our observations. Case definitions combining ICD-9 codes and medications generally lack sensitivity to capture PHN cases in administrative databases. A definition with high sensitivity is usually detrimental to the specificity [26].

Our study presents several limitations. We could not assess the validity of the diagnoses from this insurance claims database. Identification of HZ cases through ICD-9 codes is generally assumed to be a valid method, with a high positive predictive value (PPV) generally ranging between 84-100 \% in several health care plans [5, 15, 26]. In one study conducted in Veterans Health Administration Decision Support System [27], only $56 \%$ of HZ episodes identified through ICD-9 codes were confirmed as acute $\mathrm{HZ}$ after review of the medical records, illustrating that ICD-9 codes may be frequently erroneous and that the PPV may vary by data source. In addition, extensive work on algorithms for PHN detection at 3 months post-HZ onset showed that high sensitivity (80\% or more) is detrimental to the PPV $(<41 \%)$ and that the algorithm with the highest PPV (52\%) missed more than half of PHN cases (sensitivity of $45 \%$ ) [26]. There is also a risk that misclassification may have occurred for diabetes and comorbidities. The number of type II diabetic subjects $<18$ years of age seemed substantial when considering the epidemiology of type II diabetes and suggests potential classification bias. However, the impact on the study results is likely small, the number of subjects being limited.

There is a major difference of age distribution between the type II diabetic cohort and its control cohort. We did not select age as a matching factor, as it would have prevented us from analyzing the impact of age on the risk of HZ. We have therefore focused our analysis on age-stratified comparisons. The incidence of $\mathrm{HZ}$ in all age groups appears to be lower than what is usually reported in the literature for similar age groups; i.e. around 4.2-4.6 per
1,000 PY in the 50-59, 6-6.9 in the 60-69 and 8.6-9.5 in the $70-79[12,28]$. This is particularly noticeable for the age group $\geq 65$ years of age in the control cohort for type II diabetics. In the study, we excluded immunocompromised individuals at increased risk of HZ. Restricting the study population to immunocompetent individuals, we observed HZ incidences that are logically lower than in the overall population. Previous studies have shown that about $8-12 \%$ of individuals with $\mathrm{HZ}$ are immunocompromised $[11,12]$. Thus, excluding those individuals from the study does not seem to fully explain why the $\mathrm{HZ}$ incidence rates observed are lower than in other settings. The IHCIS database includes data from commercially insured individual for reimbursement purposes, and coding biases may have occurred. It is possible that the incidence of $\mathrm{HZ}$ has been underestimated in the diabetic cohorts and control groups, although we could not identify if the diabetic cohorts were affected in a different extent.

Due to a restricted number of diabetic subjects with documented HBA1c recorded results, the impact of good versus poor glycemic control was not assessed. In the casecontrol study performed using the Maccabi Healthcare Services databases, Heymann et al. had found that among individuals with documented diabetes, individuals under 45 with high levels $(>8 \%)$ of HbAlc prior to the $\mathrm{HZ}$ episode had a significantly increased risk of $\mathrm{HZ}$ compared to patients with Hbalc if $<5 \%$. No similar differences had been observed in older ages.

\section{Conclusion}

This study suggests that type II diabetes is associated with a moderately increased risk of developing $\mathrm{HZ}$ in individuals between 18 and 64 years of age. A higher risk increase was associated with type II diabetics in adults 65 years and older.

Acknowledgments The authors thank and Jarno Jansen for editorial assistance and coordinating the development of the manuscript.

Conflict of interest All authors were employed by GlaxoSmithKline at the time of study conduct.

\section{References}

1. Harpaz R, Ortega-Sanchez IR, Seward JF, Advisory Committee on Immunization Practices (ACIP) Centers for Disease Control and Prevention (CDC). Prevention of herpes zoster: recommendations of the Advisory Committee on Immunization Practices (ACIP). MMWR Recomm Rep. 2008;57:1-30.

2. Ghaznawi N, Virdi A, Dayan A, Hammersmith KM, Rapuano CJ, Laibson PR, Cohen EJ. Herpes zoster ophthalmicus: comparison of disease in patients 60 years and older versus younger than 60 years. Ophthalmology. 2011;118:2242-50. 
3. Weinberg JM. Herpes zoster: epidemiology, natural history, and common complications. J Am Acad Dermatol. 2007;57:S130-5.

4. Blank LJ, Polydefkis MJ, Moore RD, Gebo KA. Herpes zoster among persons living with HIV in the current antiretroviral therapy era. J Acquir Immune Defic Syndr. 2012;61:203-7.

5. Donahue JG, Choo PW, Manson JE, Platt R. The incidence of herpes zoster. Arch Intern Med. 1995;155:1605-9.

6. McDonald JR, Zeringue AL, Caplan L, Ranganathan P, Xian H, Burroughs TE, et al. Herpes zoster risk factors in a national cohort of veterans with rheumatoid arthritis. Clin Infect Dis. 2009;48:1364-71.

7. Pergam SA, Forsberg CW, Boeckh MJ, Maynard C, Limaye AP, Wald A, et al. Herpes zoster incidence in a multicenter cohort of solid organ transplant recipients. Transpl Infect Dis. 2011;13:15-23.

8. Rogers JE, Cumpston A, Newton M, Craig M. Onset and complications of varicella zoster reactivation in the autologous hematopoietic cell transplant population. Transpl Infect Dis. 2011;13:480-4.

9. Frère P, Pereira M, Fillet G, Beguin Y. Infections after CD34selected or unmanipulated autologous hematopoietic stem cell transplantation. Eur J Haematol. 2006;76:102-8.

10. Johnson R, McElhaney J, Pedalino B, Levin M. Prevention of herpes zoster and its painful and debilitating complications. Int $\mathbf{J}$ Infect Dis. 2007;11:S43-8.

11. Gialloreti LE, Merito M, Pezzotti P, Naldi L, Gatti A, Beillat M, et al. Epidemiology and economic burden of herpes zoster and post-herpetic neuralgia in Italy: a retrospective, population-based study. BMC Infect Dis. 2010;10:230.

12. Yawn BP, Saddier P, Wollan PC. A population-based study of the incidence and complication rates of herpes zosterbefore zoster vaccine introduction. Mayo Clin Proc. 2007;82(11):1341-9.

13. Thomas SL, Hall AJ. What does epidemiology tell us about risk factors for herpes zoster? Lancet Infect Dis. 2004;4:26-33.

14. Okamoto S, Hata A, Sadaoka K, Yamanishi K, Mori Y. Comparison of varicella-zoster virus-specific immunity of patients with diabetes mellitus and healthy individuals. J Infect Dis. 2009;200:1606-10.

15. Heymann AD, Chodick G, Karpati T, Kamer L, Kremer E, Green MS, et al. Diabetes as a risk factor for herpes zoster infection: results of a population-based study in Israel. Infection. 2008;36:226-30.
16. Joesoef RM, Harpaz R, Leung J, Bialek SR. Chronic medical conditions as risk factors for herpes zoster. Mayo Clin Proc. 2012;87:961-7.

17. Aldaz P, Díaz J, Loayssa J, Dronda M, Oscáriz M, Castilla J. Herpes zoster incidence in diabetic patients. An Sist Sanit Navar. 2013;36:57-62.

18. Lasserre A, Blaizeau F, Gorwood P, Bloch K, Chauvin P, Liard F, et al. Herpes zoster: family history and psychological stress-casecontrol study. J Clin Virol. 2012;55:153-7.

19. Tseng HF, Smith N, Harpaz R, Bialek SR, Sy LS, Jacobsen SJ. Herpes zoster vaccine in older adults and the risk of subsequent herpes zoster disease. JAMA. 2011;305:160-6.

20. Yang YW, Chen YH, Wang KH, Wang CY, Lin HW. Risk of herpes zoster among patients with chronic obstructive pulmonary disease: a population-based study. CMAJ. 2011;183:E275-80.

21. Oxman MN, Levin MJ, Johnson GR, Schmader KE, Straus SE, Gelb LD, et al. Shingles Prevention Study Group. A vaccine to prevent herpes zoster and postherpetic neuralgia in older adults. N Engl J Med. 2005;352:2271-84.

22. Pinchinat S, Cebrián-Cuenca AM, Bricout $\mathrm{H}$, Johnson RW. Similar herpes zoster incidence across Europe: results from a systematic literature review. BMC Infect Dis. 2013;13:170.

23. Leung J, Harpaz R, Molinari NA, Jumaan A, Zhou F. Herpes zoster incidence among insured persons in the United States, 1993-2006: evaluation of impact of varicella vaccination. Clin Infect Dis. 2011;52:332-40.

24. Irwin MR, Levin MJ, Carrillo C, Olmstead R, Lucko A, Lang N, et al. Major depressive disorder and immunity to varicella-zoster virus in the elderly. Brain Behav Immun. 2011;25:759-66.

25. White RR, Lenhart G, Singhal PK, Insinga RP, Itzler RF, Pellissier JM, Segraves AW. Incremental 1-year medical resource utilization and costs for patients with herpes zoster from a set of US health plans. Pharmacoeconomics. 2009;27:781-92.

26. Klompas M, Kulldorff M, Vilk Y, Bialek SR, Harpaz R. Herpes zoster and postherpetic neuralgia surveillance using structured electronic data. Mayo Clin Proc. 2011;86:1146-53.

27. Rimland D, Moanna A. Increasing incidence of herpes zoster among Veterans. Clin Infect Dis. 2010;50:1000-5.

28. Insinga RP, Itzler RF, Pellissier JM, Saddier P, Nikas AA. The incidence of herpes zoster in a United States administrative database. J Gen Intern Med. 2005;20:748-53. 